This is a post-peer-review, pre-copy edited version of an article published in Anthropology and Medicine. The definitive publisher-authenticated version will soon be available online.

\title{
Ideals, negotiations and gender roles in gay and lesbian co-parenting arrangements
}

Cathy Herbrand, Centre for Reproduction Research, De Montfort University

\section{Cathy.herbrand@dmu.ac.uk}

\begin{abstract}
This paper engages with the complex gender and parental dynamics experienced in the context of co-parenting arrangements. These arrangements, based on mutual agreement, involve people who commit to raising a child together, possibly with their respective partners. These family forms are usually pursued to avoid what is perceived as the uncertainty surrounding alternative assisted reproductive options such as donor insemination or surrogacy, and to allow the child to have two biological and sexually differentiated parental figures.

This paper explores some of the opportunities and challenges presented by co-parenting by focusing on the experiences and accounts of lesbian women and gay men engaged in such family arrangements. Drawing on work by social theorists of the family, the main characteristics of these arrangements are first examined to show that while co-parenting might first seem marginal, it appears particularly well adapted to contemporary social constraints and parenting expectations. The second part of the paper shows how in practice, dominant gender norms remain largely unquestioned and can lead to tensions and unbalanced parental power relationships between biological parents, which in turn, can present a significant challenge to these family arrangements. The analysis therefore suggests that while co-parenting offers the potential for parents to reconcile contradictory social expectations and provide them with opportunities to create family practices that suit them, these are restrained by existing gender norms, in particular by the prevailing role of the biological mother.
\end{abstract}

Keywords: reflexive negotiation, intensive mothering, gay and lesbian families, gender dynamics, heteronormativity 


\section{Introduction}

From a personal standpoint, the sacrifices it would take for me to have a child by myself, using genetic material from a friend or a sperm donor, outweigh my desire to have a child. I can, however, picture an arrangement with a man I love and care about but don't marry, someone who also wants to have a child, organizing from birth the custodial arrangements that divorced and never-married people have been honing for decades to raise children.

Emily Witt, Future Sex (2016)

Conceiving and raising a child with someone who is not a committed conjugal partner has long been disapproved of and is still regarded by some with concern or distain, whilst the nuclear family based on love remains a highly valorised model of parenting (Beck-Gernsheim 2002; Gabb and Fink 2018). Despite this context, this way of having children, referred to as 'coparenting', has increasingly become a family-building option in itself. Originally describing the cooperation of parents in raising their children after divorce, this term now also designates people who deliberately pursue this type of family arrangement and commit to raising a child together, possibly with their respective partners. Co-parenting arrangements can vary considerably, including two to four adults or more, from different genders and sexual orientations (Erera and Segal-Engelchin 2014; Herbrand 2017). Whereas this route to parenthood initially concerned mostly gay and lesbian individuals, the rise of specific websites dedicated to such arrangements and the organisation of networking events, such as 'speeddating' for prospective co-parents (Ravelingien, Provoost, and Pennings 2016), has facilitated its expansion amongst heterosexual women or men in recent years (Jadva et al. 2015). These 'co-parents' - both intended biological parents and their possible partners - need to determine and negotiate their own roles and responsibilities, as well as the practical arrangements of family organisation.

Despite this expansion of co-parenting arrangements, there is still little research exploring this phenomenon. Current studies have mainly looked at co-parents' motivations and characteristics, showing that such arrangements are usually pursued in order to avoid what is perceived as the uncertainty surrounding alternative assisted reproductive options such as donor insemination or surrogacy, and to allow the child to have two biological and sexually differentiated parental figures (Jadva et al. 2015; Herbrand 2017; Erera and Segal-Engelchin 
2014; Segal-Engelchin, Erera, and Cwikel 2012). However, there is a pressing need to understand how these new family forms work in practice, in particular regarding parental experiences and gender dynamics. These family arrangements constitute unique sites of parental experimentations where biological parenthood is created and experienced for itself, separately from romantic or sexual commitments. Co-parenting is all the more interesting given that co-parents benefit from significant leeway to negotiate, implement and manage their family arrangements due to lack of pre-established models and medical or legal procedures to follow.

In this paper, I explore some of the opportunities and challenges presented by co-parenting by focusing on the experiences and accounts of lesbian women and gay men engaged in such family arrangements. Drawing on work by social theorists of the family (Giddens 1992; BeckGernsheim 2002; Jamieson 1999), I first examine the main characteristics of these arrangements to show that while co-parenting might first seem marginal, it appears particularly well adapted to contemporary social constraints and family expectations, including in relation to intensive parenting (Lee et al. 2014). Co-parents aspire to mix dominant parenting culture with their own reflexive ideas. I then show how in practice, dominant gender norms remain largely unquestioned and can lead to tensions and unbalanced parental power relationships between biological parents, which in turn, can present a significant challenge to these family arrangements. I therefore suggest that while co-parenting offers the potential for parents to reconcile contradictory social expectations and provide them with opportunities to create family practices that suit them, these are restrained by existing gender norms, in particular by the prevailing role of the biological mother.

\section{Methods}

This paper is derived from a wider research project on multi-parenthood in Belgium, which focused on lesbian and gay co-parenting arrangements (Herbrand 2008). Given the difficulty of reaching this hidden group of parents, the study was based on a purposive sample, comprising 26 co-parents with whom I conducted extensive in-depth interviews in 2006 and 2007. There were 11 women and 15 men, aged between 28 and 52 years old, and living in Belgium. All but one co-parent were white and the majority were from middle-class backgrounds. I recruited co-parents through snowball sampling, after regularly attending gay and lesbian association meetings and events related to the debate on adoption by same-sex couples taking place at the time in Belgium (Herbrand 2006). The accounts I collected allowed 
me to analyse in detail nine distinct co-parenting cases, each including two to six co-parents (see table below). Most co-parenting arrangements involved three adults: in two cases, a lesbian couple and a gay man and in four cases, a gay couple and a single -lesbian ( $n \sim 2)$ or straight (n 2)- woman. Two co-parenting cases were also made up of two different child rearing arrangements and involved three households, i.e. that of a lesbian couple, of their first child's father and of their second child's father All but one couple relationships originated prior to the decision to have children. As most of the 11 children included in these cases were very young at the time of the research (i.e. most of them under 4 years old), I did not interview them.

Given the need to capture co-parents' respective views and to understand the negotiations taking place between different members of the family, I asked to meet all co-parents involved in a joint family arrangement, which was possible in most cases, and to interview them separately. I did follow-up interviews with seven of the 26 participants in order to gain a better understanding of how their experiences of co-parenting had developed over time. All interviews were transcribed verbatim, anonymised, and then thematically analysed (Silverman 2001). In order to identify contrasts and overlaps in the accounts, I read and coded all transcripts individually, before analysing them in comparison to the other co-parents involved in the same family configuration (Eisikovits and Koren 2010). This provided data according to thematised individual accounts, as well as allowing a case by case analysis (Taylor and Vocht 2011). Names, places and identifying details in the interview extracts have been altered.

<Table 1 here>

\section{Challenging parental ideals and expectations}

Over recent decades, social theorists have shown how family and intimate relationships have undergone significant changes in terms of definition, forms and functions, and also with regards to how they are idealised (Morgan 1996; Smart 2007; Weeks 1989; Beck and Beck-Gernsheim 1995). In the sphere of intimacy more particularly, Giddens has described how individuals, in late modernity, aim to achieve what he called 'the pure relationship', one based on electivity, auto-regulation, reflexivity and equality. Individuals are perceived to have greater freedom to choose their partner as well as to negotiate the conditions of their relationship which 'exists solely for whatever rewards that relationship can deliver' (Giddens 1992). According to Giddens, this is part, more broadly, of the ongoing 'democratisation of the private sphere' (1992, 188), which also affects parental, sexual and friend relationships. In line with this 
theoretical framework, Beck and Beck-Gernsheim have highlighted the central role of love and individual interests in intimate relationships, which simultaneously creates more instability and ruptures as relationships depend on partners' satisfaction.

Jamieson has called, however, for caution and a more complex understanding of these processes, as ideological discourses do not automatically translate in practice. According to her, 'few relationships, even friendships, are mainly simply about mutual appreciation, knowing and understanding' (1999, 482). In particular, she documents how empirical research has shown the persistence of gender inequalities, both in everyday life and at institutional levels. More importantly, Jamieson and others scholars have highlighted how the arrival of children might destabilise the couple relationship since parenting tends to exacerbate gender unbalances (Jamieson 1999; Hays 1998; Mannay 2015; Sevón 2012). Despite discourses promoting equality and shared domestic and parental tasks between both parents, mothers usually remain the child's main care-giver, in particular in contexts where much pressure is currently put on maternal bonding and prolonged breastfeeding (Faircloth 2013).

This 'intensive and embodied motherhood' is part of and contributes to the prevailing middleclass culture of 'intensive parenting'(Lee et al. 2014), which encourages parents to be fully dedicated to the child, reflexive, informed and accountable for their decisions, not only once they become parents but even before conception. Parents are regarded as responsible for the future of their child. As Faircloth and Gürtin point out, 'this rule-bound reproductive and parenting landscape is in many ways contrary to the increasingly fluid, creative and elective landscape of 'do-it-yourself' adult intimate relationships' (Faircloth and Gürtin 2017, 6). In addition, 'fathers have not been immune from this trend towards a more 'intensive' style of parenting, but it remains mothers to whom these cultural messages are largely targeted, and around women's reproductive choices that the fiercest debates reign' (Faircloth and Gürtin 2017 , 4). This can be especially overwhelming and frustrating for mothers, in particular if they value and expect gender equality. It is important to note, of course, that these difficulties in sharing equally domestic and parental tasks are not absent from gay and lesbian families either. While many lesbian and activist works have insisted on the gender symmetry and the search for equality within lesbian couples and families (Sullivan 2004; Dunne 2000), Gabb showed how a more nuanced approached is needed in this field and that challenging gender norms does not necessarily involve egalitarian sharing of domestic and parental tasks(Gabb 2005).

Parents, moreover, need to articulate these ideals guiding personal life with those prevailing in public and professional spheres, i.e. performance, flexibility, autonomy and independence. 
Beck-Gernsheim shows how parents are therefore caught between a number of incompatible demands: being influenced by ideals conveyed by the 'pure relationship', encouraged to be competitive and successful at work, having a satisfying social network, and simultaneously, engaging in intensive parenting (Beck-Gernsheim 2002).

\section{Well-adjusted contemporary families}

As illustrated by examples from my study, co-parenting can facilitate the achievement of a number of the ideals and expectations highlighted above, including: the biological heteronormative family model, the possibility to negotiate and implement reflexive parental practices, the need for a committed but personalised parenthood, as well as the desire for a better and more flexible life-balance.

\section{The primacy of genetic parenthood and the 'mum and dad' family model}

As for many individuals for whom conceiving children is not straightforward, either because they are in a same-sex relationship, have no partner, or infertility problems, the co-parents I interviewed had to make reproductive decisions based on several available options. Each of these options had their advantages and drawbacks in terms of practical and legal requirements and implications. Most importantly, each of them aligned or conflicted with particular personal values and family ideals. As Lewin mentions in her studies of lesbian mothers, 'the method a woman chooses for becoming a mother is as vital a part of her objectives as her desire to be a mother. These methods are not only a means to an end, selected for reasons of convenience, but vehicles for crafting statements about the self [...]' $(1995,112)$.

Lewin's statement can be extended to the gay men and lesbian women I interviewed. It was quite clear that they chose this route to parenthood because of specific family ideals and after giving it much consideration. None of the participants mentioned legal or financial reasons for pursuing co-parenting. In many cases, they could have opted for adoption or assisted medical reproduction, which are permitted in Belgium and could have been more convenient, at least for lesbian couples ${ }^{1}$. In spite of those possibilities, they worked to achieve a family configuration in compliance with their values and identity. As I explain in more details elsewhere (Herbrand 2017), there were four recurrent reasons given by participants for choosing co-parenting: the desires for a biological descent, to experience pregnancy for women, to know the child's background and most importantly, to provide the child with a mother and a father. 
Significantly, most co-parents said they would not have been satisfied with adopting a child, as it was crucial for them to have 'a child of their own' with whom they shared biological connectedness. Denis explained: 'I want it to be my child, and by that I mean a biological part of me". Co-parents' preferences reflected broader family ideals prevailing in a culture valuing and emphasising genetic relationships (Carsten 2004; Nordqvist 2017). This need for a biological child was also closely related, for many women I interviewed, to a desire to share bodily connections with the child through pregnancy and breastfeeding. Most co-parents insisted, however, that they were reluctant to use reproductive medical assistance. Despite valuing conventional parental ideals, this was not a matter of disapproving the use of reproductive technologies as potentially 'unnatural'. All of them had indeed used selfinsemination to conceive their child at home, i.e. some kind of 'assisted' reproduction. This was not either an attempt to avoid medical treatments or clinical settings as such. Rather, most co-parents rejected the use of external genetic material from someone who would not be part of the intended family configuration and play a role in childcare. In particular, female participants in my study expressed different kinds of fears regarding the uncertainties surrounding sperm donor conception. Not only did they want to know the child's medical history, but they also felt uncomfortable imagining them or the child possibly meeting the donor or donor-conceived siblings without being aware of it (Herbrand 2017). As Charlotte explained, using an unknown donor would generate too many questions and anxieties that she did not feel ready to face:

You don't know what is being concocted behind the scenes. You don't know where the sperm comes from, who gives it... there are too many unknown factors, it's too much. Finding a 'known donor' or an 'accessible surrogate' who could supply the child with information about origins was nonetheless not sufficient for the interviewed co-parents. What many really wanted was for the child to be raised by both biological parents, including the biological father, with whom he or she could develop significant and lasting relationships. Parenthood had to be embodied. This was often part of the family model they might have known themselves and wanted to reproduce. Moreover, as Michael, a biological father, added: 'It makes integration easier. A father and a mother, it is not essential, I think, but if it is possible, it's easier for the child with respect to the outside'.

Although my study focused on gay and lesbian co-parenting arrangements in Belgium, existing studies (Erera and Segal-Engelchin 2014; Jadva et al. 2015) converge in showing that the main reason individuals, either gay or straight, pursue co-parenting in different contexts is the desire 
to provide the child with an involved mother and a father. Segal-Engelchin et al. (2012) indicate that the single Israeli heterosexual female co-parents they interviewed were also motivated by the practical and financial facilities offered by the family arrangements but their initial motivation was still to maintain the 'two-gender parenting'.

The discourses through which co-parents' accounts are constituted reflect a powerful set of ideals associated with biogenetic relatedness, maternal bonding and the heterosexual family. As Faircloth and Gürtin observe (2017), these ideals are still imbued with middle-class values, despite the diversification of family forms. Co-parenting therefore offers the opportunity to achieve these ideals and re-align with the conventional heteronormative family model, while simultaneously challenging parental prevailing norms, such as the single-family household. In this respect, it is important to note that medically assisted options such as use of sperm donation, could not entirely fulfil these needs, as they would not provide the child with parental involvement from both biological parents. This is why some individuals, like the gay men and lesbian women I interviewed, often spent a long time looking for potential co-parent(s) with whom to conceive a child. This reminds us how new family forms do not necessarily require the use of reproductive technologies.

\section{Auto-regulation, negotiation and reflexivity}

The co-parents I interviewed, in particular those who instigated the arrangement, had spent a lot of time considering and planning their family situation. This is not particular to co-parents as reflexivity and accountability are increasingly expected from would-be parents, in particular from those who wish to adopt or conceive a child through medical assistance. Prospective parents need to demonstrate their capacities to be 'responsible reproducers' and to behave as 'actual mothers and fathers' even before becoming parents (Faircloth and Gürtin 2017; De Graeve 2012). Authors have also shown that gay and lesbian individuals are more inclined to reflect upon and query their parental practices, not only because 'the reproductive process requires couples to make explicit their choices about the family they seek to become' (Nordqvist 2012, 646) but also as they especially tried to perform 'good parenthood' in environments where gay and lesbian parenting might still be regarded with suspicion (Donovan and Wilson 2008; Dunne 2000; Mamo 2007).

The particularity of co-parenting was, however, characterised by my participants as one without intervention from any social or medical institution. Unlike with adoption or medical assistance, co-parents do not have to be scrutinised and follow specific rules or procedures imposed by an external institution. This enabled co-parents' to follow their preferences, but 
also forced them to reflect on what kind of family and parental role they wanted, and how to make these happen in practice. In addition, all aspects of the family arrangement had to be negotiated, agreed on and implemented between both biological parents and their possible partners. These included each parent's responsibilities as well as the practical and ideological orientations of the child's education and upbringing (e.g. the housing arrangements, the financial costs and the choice of school).

Most co-parents I interviewed tried, as much as possible, to discuss and plan the important steps and dimensions of the arrangement before child's conception to avoid disappointment or conflicts later on. These decisions could be quite delicate and complex though, especially when more than two people were involved in the discussion. Claire recalled, for instance, how she, her partner and the child's future biological father talked for a long time about the possibility of baptising their child. Although this was something important to her because of her Catholic background, she eventually gave it up as the other co-parents were opposed to this idea. Similar discussions and negotiations happened, John told me, about vaccination and organic food and they all had to make concessions to find an agreement. Once the main elements of the arrangement had been agreed upon, it was frequent for co-parents to indicate these decisions in a shared document. This informal 'charter' was used as a means to reflect on and record their choices, rather than as a form of binding contract.

Prior to the birth of the child, co-parents also often invested significant time and effort in getting to know each other better to secure the foundation of the family relationship which they sought to build. For instance, Michael described how he and his lesbian friend couple organised roleplaying games between the three of them in order to anticipate and discuss each other's reactions about the child's education and food habits, amongst other things. As Michael said, 'of course, it will be different in real life but it already gave us an idea of how we would react'. They also met other co-parents to better understand how this relationship could work in practice. These mechanisms of anticipation and reflexivity were all the more important since the rise of co-parenting websites had enabled co-parenting between people from different backgrounds and sometimes from different countries (Jadva et al. 2015, 1897). Indeed, while co-parents in four of the nine cases included in my study were friends and knew each other relatively well before discussing the possibility of having a child together, the other participants met through specific meetings or websites for prospective co-parents. One case of co-parenting I studied was actually taking place across France and Belgium and the co-parents had put a complicated housing system in place to manage the child's circulation between them. In 
another case, the biological mother recalled how she and her partner were keen to parent with a French gay couple they had met online and found very nice. They nonetheless realised after a few months of contacts and interactions that the distance would make the arrangement too difficult to sustain and they reluctantly had to abandon it.

As these examples illustrate, co-parenting cases constituted very reflexive and personalised family arrangements, where individuals were inclined, or at least encouraged, to be openminded and to demonstrate respect, forward-thinking and conciliation. This reflects more broadly the 'processes of reflexive negotiation' described by Beck and Beck-Gernsheim (2013), whereby individuals need to create and implement their own family practices given the absence of pre-established models and rules for their particular situations. These parental reflexive negotiations are increasingly present and required in a number of families, such as co-parenting ones, whose boundaries and mode of functioning need to be explicitly defined (Hudson 2017).

\section{Personal preferences, adjustable roles and parental commitment}

Intention and individual preferences were key in the co-parenting cases I studied. All the coparents I interviewed insisted on the importance of respecting everyone's personal desire to have children and to consider the extent to which each co-parent wanted to be involved. As mentioned earlier, the possibility of considering and following personal preferences was facilitated by the absence of intervention from any social or medical institution. Parental roles were therefore not left assumed, but were open to reflection, critique and planning.

As for the biological parents I interviewed, they always wanted for the two of them to be actively present in the child's life and to become the legal parents. All biological fathers therefore recognised the child at birth and were highly involved when the child was staying with them, assuming all the usual childcare tasks. While this directly aligned with the family model co-parents valued - one that is based on two sexually differentiated parental figures and was agreed by all of them from the outset, it differed significantly from most donorconceived lesbian families where the biological father, if known, usually occupies a more marginal position (Donovan and Wilson 2008; Haimes and Weiner 2000; Ryan-Flood 2009).

The role and responsibilities of the respective biological parents' partners were subject to more discussion and negotiation, as their desire to have children varied considerably. If most female partners I interviewed shared the biological mother's desire to have children ${ }^{2}$, the male partners' feelings and views about parenting were mixed, some of them stating clearly that they 
were not ready to take care of a child but could support and accompany the intending biological father in his parental project. Whenever possible, co-parents therefore tried to define parental roles which would fit with the particular needs and desires of each biological parents' partner. Female partners usually wished to be very involved with the child, often to the same extent as the biological mothers, either in terms of decision-making or caring activities. Reflecting Dalton and Bielby's findings on lesbian couples (2000), 'the[ir] decision to become parents figure[d] centrally in each partner's commitment to the relationship'. However, unlike what happens frequently in lesbian-headed two-parent families (Dalton and Bielby 2000), female partners in co-parenting arrangements often defined their role as that of a 'parent', insisting that they were not a 'mother'. This role was indeed perceived as unique and distinct because of the biological relationship to the child. Nearly all co-parents I interviewed considered that the biogenetic tie both biological parents shared with the child granted them privileged and specific symbolic parental statuses and thus did not attempt to challenge this by creating equality between both partners. Their initial commitment and their full parental engagement were especially important elements for the partners of the biological mothers and constituted a defining element of their parental identity. None of them wished, for instance, to be regarded either as a step-mother or a god-mother. Claire, a female partner, explained that adopting the status of a 'god-mother' would have facilitated her recognition towards the child, but it would not have reflected her role and her tie to the child in a satisfying way. She also insisted that her role could not be compared to that of a step-parent:

I believe that my role is more important than that of step-parents, because, well, I was there since the very start. I am not in a situation that I didn't want. This is a situation that I really wished for. It is very different; I have taken the train at the same time as the others.

The role and responsibilities of the male partners I met were, however, more diverse and changing over time. They were rarely the ones who instigated the co-parenting arrangement and they usually got less involved with organising co-parenting. For instance, Anthony did not initially wish to be involved in taking care of the child but he perceived himself as a 'co-father' who took part in the decision and played a secondary parental role in the child's life. As the child grew up, Anthony explained that he got more attached to the child and thus also more involved both in everyday caring tasks and on the long term, as he adapted his will in favour of the child. 
Others, like Ken, initially felt a bit 'scared' at first and did not wish to get too involved with the child. He preferred to 'assist' the arrangement, as he said, by supporting the biological father in his role of father and give his opinion about the decisions made between both biological parents:

I have a 'consultative position' somehow... and this fits me very well. [...] I consider myself rather as a 'co-father' than a 'step-father' because there hasn't been any breaking and re-construction. It was John [the biological father]'s desire that I joined. We have shared the adventure together and I have seen the child evolving with his Mum and Dad since the very start.

Again, the early commitment of the biological parents' partners in the family arrangement constitutes a key element that they were keen to emphasise and foreground. It created and marked the specificity of their parental position and connection to the child. If parental commitment was crucial in participants' views, it did not necessarily imply a full engagement in raising a child. In the context of co-parenting, it meant agreeing to be part of the family arrangement from the outset and committing to play a role in the child's life at some level - be it in terms of decision-making, caring activities, advice or responsibilities, as well as to respect and apply the principles and decisions which had been collectively adopted. These commitments were always private and informal, at most recorded in the informal 'charter' mentioned earlier. This document did not have any contractual or legal liability though.

The importance granted by all co-parents to parental commitment echoes current social expectations for parents to respect and fully endorse the parental engagement and responsibilities they have taken. In Western societies where contraception and reproductive technologies are often available, having a child is indeed no longer supposed to be - or at least be presented as - an 'inevitable accident', but rather a 'conscious choice' that individuals are required to make for themselves and then take responsibility and be accountable for. In this respect, co-parents affirmed their choice of wanting to have children and being entitled to have them, despite their sexual orientation or the relationship status. Moreover, while co-parenting might not initially have represented their ideal option to have a child in other circumstances, it enabled them to create and experience parental roles more in line with their own desires, to adjust these roles to their preferences and needs. This can be seen as an advantage of these family arrangements with respect to more conventional families where respective roles and responsibilities might often be taken for granted and less openly and thoroughly discussed. 


\section{Flexibility, work-life balance and child-centered parenting}

Interestingly, participants often stressed the -unexpected- advantages co-parenting brought to their life in terms of time management because of the possibility of sharing the child's upbringing and residency between the co-parents. This was of course highly influenced by the type of arrangement they would put in place but again, co-parenting offered a certain flexibility in this respect and unlike divorced parents, co-parents did not have to follow specific legal requirements regarding the child's residency. Besides practical constraints, they could, in theory, opt for any arrangement that suited them. In practice though, most co-parents opted for an arrangement in which the child would live with their mother during the week and would spend every other weekend and perhaps Wednesday afternoons with the father ${ }^{3}$. In one case only, the housing was shared equally between both biological parents. The child's holidays were also usually shared between both parents and sometimes, some co-parents spending part of their holidays all together, i.e. the child with both biological parents and their possible partners.

In two cases where the children were still very young, co-parents took the opportunity to experiment with implementing more flexible and innovative childcare arrangements which would fit with their life and work constraints. One of these cases included both biological parents and the mother's partner. They decided from the outset that they would tried to share everything they could equally between the three of them, including expenses, responsibilities and caring activities. In order to achieve this in practice, they met at the beginning of each month and planned with whom the child would be on a daily basis. Although they lived quite far away from each other, they also tried to spend time the three of them with the child whenever this was possible. In the other case where flexible arrangements were implemented, the three co-parents had decided to live in the same street and would take turns to go and collect the children at the nursery according to their work obligations.

If this appears complicated, especially when arrangements had to be made between three households ${ }^{4}$, the co-parents I interviewed usually highlighted the advantages of these shared childcare systems, as long as the initial arrangements and principles were respected (see below). Even when they had difficulties in getting used to these arrangements initially, many co-parents, both men and women, said that they eventually greatly appreciated the spare time they had when the child was not with them. It allowed them to better balance the parental, conjugal and personal dimensions of their life knowing that the child was always in a safe place. Time could be devoted to their children but weekends or even weeks could be free for 
themselves. This system also allowed some co-parents who had variable or busy working lives to better manage professional and family life, by sharing and adapting their child's housing arrangements to professional constraints. This is why some families decided to repeat the arrangement for the second child. For instance, in one case, the lesbian couple wanted to have a second child but the first child's father was not ready for that. The women therefore turned to another gay friend with whom they then had their second child. They described the second family arrangement as a 'copy-and-paste' of the first one. According to these participants, children complied very well with this. It had enable them to be mobile and to adjust easily to different environments from an early age.

Simultaneously, these arrangements also encouraged co-parents to maximise their time with the child when it was their turn. Both biological parents emphasised how their lives and priorities were then primarily centred around the child. Although they were not subject to any direct supervision or counselling like intending parents opting for adoption or donor conception, I observed how most co-parents, especially the biological parents, tried to fit with norms of 'good parenting', looking for recommendations on how to best feed children or to provide the most up-to-date care treatments (Lee et al. 2014). They regularly referred to specialised books or forums they had consulted for advice on child upbringing, breast-feeding, maternal bonding, etc. Several co-parents also highlighted how co-parenting could offer some educational advantages and contribute to enrich the child's life by benefitting him or her with different family and cultural environments. For instance, Anne was very happy that the child could learn and speak another language with his father, who was a German native speaker. This appear as one way of 'optimising' the child's development and opportunities for the future. Achieving 'good parenting' seemed especially important for participants in my study, as they were well aware of social scrutiny and possible stigma affecting gay and lesbian families. Some of them mentioned, like Michael, how he 'wanted to prove that it is also possible to have a family who works well'.

\section{Re-essentialising gender roles}

Co-parenting, which can seem marginal at first glance, is therefore well-adapted to current societal constraints and intense 'parenting culture', while allowing the implementation of the more traditional family model based on genetic parenthood and the sexually differentiated parental figures. It presents, moreover, significant advantages for co-parents by offering them some flexibility, a better work-life balance and personalised parental roles. Co-parents' 
relationships are, however, also shaped by more traditional gender dynamics, which can have significant implications on all aspects of the arrangement.

\section{The primacy of maternal connection}

The main reason for unbalanced gendered relationships was that the biological mother's predominant role and presence usually remained unquestioned. As explained elsewhere (Herbrand 2017), the biological mother was indeed perceived as playing an essential role in the child's life, not only because of her perceived 'natural' ability to take care of the child but also because of the special physical bond she had created with the child through pregnancy and breastfeeding, something that the biological father was seen as lacking. According to Steve, a biological father:

A child, in the beginning, he needs more his mum than his dad, for the feeding, the night... He comes out of his mummy's tummy, it's not to end up on someone else's body, on someone who has no breast.

Michael, another biological father also mentioned this 'maternal instinct' when he was explaining how the biological mother, unlike him, had spotted that the child had chicken pox. He added: "I am not in favour of saying: "this is for the man, this is for the women", but it is how I have been educated!'. Michael's comment reflects a common tension in participants' accounts: most co-parents were simultaneously in favour of gender equality, while essentialising abilities and roles when it comes to parenting.

At times, the importance and priority granted to the biological mother would lead to decisions and situations where men were at a disadvantage, creating possible tensions between coparents. These tensions were especially perceptible and expressed around the child's housing arrangements. As mentioned earlier, although co-parents had much leeway in this respect, it turned out that the child was usually living most of the time with the mother. While all the interviewed co-parents confirmed they agreed with this arrangement, it appeared, however, that the decisions regarding the housing arrangements tended to have been first discussed and planned by the biological mother or by the lesbian couple, before talking them over with the child's father. For instance, Deborah, a single mother, explained how when she met Bob, who would become the father of their child, she stated her conditions regarding the child's housing:

I didn't want to go further in a project where my child could be taken away from me. This really worried me, so I was trying to test the water. [...] Then, when we met, the first thing I said was: 'Listen, you have to know that for me, 
there is no question about it, there won't be shared custody. It will be [...] every other weekend and Wednesdays afternoons'. As for him, he was being offered a dream on a silver plate.

Things were usually not said so bluntly and straightforwardly by the biological mother. Liz, for instance, recalled how she and her partner tackled this issue with the gay couple who were presented with the co-parenting proposition:

Question: Have they expressed any demands?

Not many actually, not many because we've already had, if you want, a type of well-set model and a well-defined plan, that was half of the holidays and every other weekend. Anyway, we were a little stressed to suggest to them something which we had already worked out in our mind and that we might have had to change. When they agreed, they agreed for everything.

Interestingly, these asymmetrical housing arrangements were generally well received by the fathers, at least initially. Most fathers said they were very happy to have the child, even on a part-time basis since it already offered them, as seen earlier, the opportunity to be present in the child's life and spend some quality time together. Some fathers even preferred the mother to handle the practical aspects of the parenting arrangement. This solution suited Jeff, for instance, who explained that 'even if it isn't the case anymore, I liked going out, among other things. I thought it was fine every other week-end'.

Peter, on the other hand, was more reluctant about this arrangement at first. He feared it would be difficult for him to spend so much time separated from his child. He then spoke to some friends who were already involved in a co-parenting arrangement and asked them how they experienced this situation. They responded that 'it was actually not easy but anyway, it is the only possibility offered to you'. As implied here, as well as in Deborah's account quoted above, co-parenting does not present the same opportunity to men and women who want to have children. It is more difficult for men to turn to adoption or to surrogacy for social, economic, and legal reasons, particularly in Belgium where clinics did not offer surrogacy for single men and gay couples until recently. They therefore are more restricted in their options to have a child. As the biological fathers in my study told me, when a co-parenting proposition was presented to them, it often constituted a unique and unexpected opportunity to become a father, particularly if they wanted the mother to be involved in the child's life. Consequently, they 
were more inclined to make concessions over the decisions regarding the family organisation ${ }^{5}$ and, like Peter, accepted or convinced themselves that it was a good thing for the child:

Question: And now, are you still a little apprehensive about the situation?

No, no. On the contrary, I think it is fine because, in retrospect, I realise that it is important for a child to be with his mother in the beginning. Whether it is a boy or a girl, it's important. Let's be honest about that, the link is really strong with the mum from the beginning. And frankly, I believe it is a good arrangement.

The maternal biological and bodily connection was foregrounded not only to justify the chosen asymmetrical housing arrangement but also the adoption of an 'initial transition arrangement' when the baby would stay at the mother's place during the first months and sometimes the first years after birth, before the final agreed housing system would progressively shape up. According to the co-parents, this would allow mothers to breast-feed and to take care of the infant, while maintaining some stability during this period. The father would see, bathe, and bottle-feed the child at different times. After a few months, the father would take the child to spend one afternoon at his home, then a whole day until the child would finally sleep over. The child could therefore slowly adapt to the changes of family environments.

\section{Intensive mothering and gender dynamics}

The fathers I met had mixed feelings about this transition period. Some admitted they had a hard time not to see more of their child, even it was sometimes a relief not to have to take care of the child during the night. Most fathers I interviewed tried to eventually accept the situation and focus on its positive sides, as Jeff mentioned earlier. However, in four cases, these tensions increased significantly when the biological mother decided to extend this transition period or asked to modify the initially agreed housing plan.

After giving birth and taking care of the child for a few months, several mothers I interviewed told me they no longer felt ready to separate from the child. They said they had underestimated the length of this period, and that it would be better for the child to stay longer with them. For instance, Susan explained that she had always wanted a father for her future child. She first was very keen to have this child with the gay couple she and her partner Charlotte had met through an online forum. The four of them regularly met before conceiving the child but once pregnant, Sabine started having many doubts about the parental arrangement and their relationship with the gay couple: 
When I became pregnant, I felt that I needed to be just with Charlotte at our place. I suddenly wondered about what I had done. They [the gay couple] were there and I wanted them to disappear. [...] I was thinking: 'I am going to have to give my child, to share her. How am I going to do this?

Susan no longer felt that she was ready to have the gay couple present in their life - for instance, she no longer wanted for both men to attend the child's home birth as she had initially suggested- or implement a shared custody as the gay couple expected. In hindsight, Sabine believed that she had been too 'euphoric' by the possibility to have a child and regretted not to have set clear deadlines and written down decisions. She said that she was too afraid that addressing sensitive topics directly could have jeopardised the co-parenting arrangement. She added, while crying, that she was still scared how things were going to evolve in the future. While the shared housing arrangement was supposed to start six months after birth, her daughter had still not stayed overnight at the father's home after one year.

By contrast, the single women I interviewed often complained about feeling lonely during their pregnancy. They had expected for the child's father to be more thoughtful and present. However, once the child was born, most of them also found it very difficult to separate from the child and the transition period lasted longer that what had been planned. The need for prolonged breastfeeding was often mentioned as a reason to extend this transition period but several mothers I interviewed also referred to psychological or paediatric studies on maternal attachment to explain that it was not good to remove the baby too soon from the mother, particularly not overnight.

This situation could cause significant tensions and all parties suffered. In particular, the fathers who happened to be in that situation told me that they felt prevented from building a strong and steady relationship with the child. This was the case of Brian, the biological father of Susan's daughter mentioned earlier. According to Brian, it was clear from the outset that he wanted to be an involved father and have his child living at his place half of the time. He therefore felt frustrated not to be able to have her staying over during more than one year. This also made his recognition in his new role as a father by the family and relatives more difficult as he was rarely seen with the child at his home or at family events.

These asymmetrical housing arrangements had also tangible consequences on the relationship the partners of the biological parents were able to establish with the child. As mentioned earlier, significant differences were noticeable between the mother's and father's sides in this respect. 
If the prior existence or absence of desire to have a child clearly influenced one's own parental involvement and commitment, the chosen housing arrangement was of utmost importance too. Indeed, female partners had more opportunities to interact with the child and create meaningful relationships, whereas the restrained time spent with the child did not help the fathers' partners to take a child-rearing role and becoming more committed towards the child, especially during the early months and years.

At the same time, the biological mothers who experienced these problematic situations ended up torn between conflicting ideals: their desire to have the central role in the child's life and their wish to provide her child with an involved and attentive father. While striving to have the priority over the child enabled them to benefit from some privileges and to have more control over the family organisation, this made them subject to more responsibilities than the father and her partner. This could be especially frustrating for these mothers as co-parenting might have been the opportunity to share out parenting tasks and responsibilities, as well as to deliver mothers from being the primary children's care-givers. Due to these conflicting ideals, some mothers found themselves caught unwillingly in these pervasive and intensive mother-child relationships, reproducing therefore unexpectedly tensions and difficulties experienced more broadly by many mothers (Lee et al. 2014; Thomson et al. 2011; Faircloth 2013).

However, it is important to point out that these tensions and problems occurred in about half the co-parenting cases I studied. Although the maternal and paternal roles tended to be essentialised and the biological mother occupied a privileged situation, it did not necessarily engender difficulties. Many co-parents were getting along well and their arrangement proceeded without major issue, sometimes several years after the child was born and in one case, even after the separation of the lesbian couple. This might partly be explained by the fact that most co-parents I interviewed had known each other for a long time and had sometimes been friends beforehand. Moreover, even in the problematic cases described above, there rarely was an 'open conflict', not only because of the father's goodwill but also because both parents usually wanted to maintain the parental arrangement and to keep collaborating. Their relationships were indeed complex and reciprocal. Most mothers I met wanted a present father in the child's life and in some cases, wished to have another child with the same father. Maintaining good relationships however proved at times more difficult to concretise in practice than these co-parents had expected. 


\section{Conclusion}

When examined as a parental mode in itself, the characteristics of co-parenting appear to conform particularly well to the prevailing ideals of flexibility, personalised choices, autoregulation and work-life balance promoted both in contemporary social life and in intimate relationships (Giddens 1992; Beck and Beck-Gernsheim 1995). Co-parents were able to combine dominant parenting culture norms with their own family ideals and parental preferences. While providing the child with the more traditional mother-and-father parental figures, this family configuration also helps to achieve contemporary expectations of intensive, reflexive, committed, child-centred and shared parenting (Lee et al. 2014; Faircloth 2013; Hays 1998). It indeed encourages both biological parents to be actively involved with the child and assume all range of parental responsibilities and caring-tasks. Of course, as this 'shared parenting' does not happen simultaneously and to the same extent between the father and the mother, it does not offer the 'egalitarian sharing' of parenting tasks which many women wish for. However, it still provides the mother with the opportunity to alleviate caring and parenting responsibilities, enabling her to keep some time for herself. Co-parenting seems therefore to constitute a family route which is particularly well adapted to the 'competing and often incompatible demands' individuals are faced with in the family and work spheres (BeckGernsheim 2002).

Co-parenting did enable a number of participants to reconcile prevailing expectations in the socio-professional domain with those of the private sphere and to find a better balance in their life. This does not mean that they all achieved this in practice or that it works well at all levels. The analysis illustrates how more traditional gender norms continue to prevail and shape coparents' family dynamics, in particular by essentialising the mother's role and emphasising her responsibilities. It needs to be pointed out, however, co-parenting as such tends to prompt these gendered processes when it is chosen by individuals who precisely value the conventional twogender parental references and perceive the maternal connection to the child as specific. Coparents, whether homosexual or straight, could have opted for another route to parenthood, even if they were single.

If these conventional gender norms did not cause any problem to some interviewed co-parents, they did, however, significantly challenge co-parenting arrangements for others. In these cases, several biological mothers appeared somehow to be 'trapped' by their own ideals, having difficulties to combine their need for an engaged father with their desire to develop and maintain an exclusive embodied connection with the child. This shows, again, how gender 
norms, in particular when it comes to parenting, remain dramatically pervasive, even for people who are seeking and defending egalitarian values in the rest of their life.

Overall, whereas co-parenting arrangements are diverse, sometimes complicated and even conflictual, they might increasingly develop as an attractive family model, in particular for single people, as suggested by Emily Witt's quotation opening the introduction. Co-parenting has the potential to offer significant advantages in modern life and help individuals cope and fit with the challenging contemporary parenting expectations. There is undoubtedly a need for more research in this area in order to better understand the parental experiences and dynamics taking place in these family situations.

\section{Acknowledgements}

I would like to thank the colleagues and friends who have provided helpful comments and suggestions on early drafts. I am especially grateful to Kylie Baldwin, Lorraine Culley, Carrie Friese, Nicky Hudson and Frederic Malherbe for their valuable insights. Thanks also to the families who agreed to take part in my research and made this study possible.

This research was funded by an ASP research fellowship of the National Belgian Scientific Research Funds (F.R.S.-FNRS) and carried out in accordance with their usual protocol around ethical approval (granted by the researcher's supervisor), in collaboration with the Université libre of Bruxelles. All research participants have given informed consent to participate in the research.

No potential conflict of interest was reported by the author.

\section{References}

Beck, Ulrich, and Elisabeth Beck-Gernsheim. 1995. The Normal Chaos of Love. Cambridge: Polity Press.

- 2013. Distant Love. Polity.

Beck-Gernsheim, Elisabeth. 2002. Reinventing the Family: In Search of New Lifestyles. Polity Press.

Carsten, Janet. 2004. After Kinship. Cambridge: Cambridge University Press. 
Dalton, Susan E., and Denise D. Bielby. 2000. “"That's Our Kind of Constellation': Lesbian Mothers Negotiate Institutionalized Understandings of Gender within the Family." Gender \& Society 14 (1): 36-61.

De Graeve, Katrien. 2012. Making Families'. Parenting and Belonging in Transnational Adoption in Flanders'. Ghent: Ghent University.

Donovan, Catherine, and Angelia R. Wilson. 2008. "Imagination and Integrity: DecisionMaking among Lesbian Couples to Use Medically Provided Donor Insemination." Culture, Health \& Sexuality: An International Journal for Research, Intervention and Care 10 (7): 64965.

Dunne, Gillian. 2000. "Opting into Motherhood: Lesbians Blurring the Boundaries and Transforming the Meanings of Parenthood and Kinship." Gender \& Society 14 (1): 11-35.

Eisikovits, Zvi, and Chaya Koren. 2010. "Approaches to and Outcomes of Dyadic Interview Analysis." Qualitative Health Research 20 (12): 1642-55.

Erera, Pauline I., and Dorit Segal-Engelchin. 2014. "Gay Men Choosing to Co-Parent with Heterosexual Women.” Journal of GLBT Family Studies 10 (5): 449-74.

Faircloth, Charlotte. 2013. Militant Lactivism? Attachment Parenting and Intensive Motherhood in the UK and France. 1 edition. New York: Berghan.

Faircloth, Charlotte, and Zeynep B. Gürtin. 2017. "Fertile Connections: Thinking across Assisted Reproductive Technologies and Parenting Culture Studies." Sociology, 0038038517696219.

Gabb, Jacqui. 2005. "Lesbian M/Otherhood Strategies of Familial-Linguistic Management in Lesbian Parent Families.” Sociology 39 (4): 585-603.

Gabb, Jacqui, and Janet Fink. 2018. Couple Relationships in the 21st Century - Research, Policy, Practice. Palgrave Macmillan.

Giddens, Anthony. 1992. The Transformation of Intimacy. Sexuality, Love, and Eroticism in Modern Societies. Cambridge, UK: Polity Press. 
Haimes, Erica, and Kate Weiner. 2000. “"Everybody’s Got a Dad...' Issues for Lesbian Families in the Management of Donor Insemination." Sociology of Health \& Illness 22 (4): 477-99.

Hays, Sharon. 1998. The Cultural Contradictions of Motherhood. Yale University Press.

Herbrand, Cathy. 2006. "L'adoption Par Les Couples de Même Sexe." Courrier Hebdomadaire Du CRISP (Centre de Recherche et d'informations Sociopolitiques), no. 19111912: 72p.

— 2008. "Les Normes Familiales à l'épreuve Du Droit et Des Pratiques: Analyse de La Parenté Sociale et de La Pluriparentalité Homosexuelles.” Bruxelles: Université Libre de Bruxelles.

- 2017. "Co-Parenting Arrangements in Lesbian and Gay Families: When the 'mum and Dad' Ideal Generates Innovative Family Forms." Families, Relationships and Societies. https://doi.org/info:doi/10.1332/204674317X14888886530269.

Hudson, Nicky. 2017. “Making 'Assisted World Families'? Parenting Projects and Family Practices in the Context of Globalised Gamete Donation." Sociological Research Online 22 (2): 4 .

Jadva, V., T. Freeman, E. Tranfield, and S. Golombok. 2015. "FFriendly Allies in Raising a Child': A Survey of Men and Women Seeking Elective Co-Parenting Arrangements via an Online Connection Website.” Human Reproduction 30 (8): 1896-1906.

Jamieson, Lynn. 1999. "Intimacy Transformed? A Critical Look at the 'Pure Relationship'.” Sociology 33 (3): 477-94.

Lee, Ellie, Jennie Bristow, Charlotte Faircloth, and Jan Macvarish, eds. 2014. Parenting Culture Studies. Basingstoke and New York: Palgrave Macmillan.

Lewin, Ellen. 1995. "On the Outside Looking in: The Politics of Lesbian Motherhood." In Conceiving the New World Order: The Global Politics of Reproduction, edited by Faye D. Ginsburg and Rayna Rapp, 103-21. Berkeley: University of California Press.

Mamo, Laura. 2007. Queering Reproduction: Achieving Pregnancy in the Age of Technoscience. Durham, NC: Duke University Press. 
Mannay, Dawn. 2015. “Achieving Respectable Motherhood? Exploring the Impossibility of Feminist and Egalitarian Ideologies against the Everyday Realities of Lived Welsh WorkingClass Femininities.” Women's Studies International Forum 53 (November): 159-66.

Morgan, David H. 1996. Family Connections: An Introduction to Family Studies. Cambridge, UK: Polity Press.

Nordqvist, Petra. 2012. “'I Don’t Want Us to Stand out More than We Already Do': Lesbian Couples Negotiating Family Connections in Donor Conception.” Sexualities 15 (5-6): 644-61.

—. 2017. "Genetic Thinking and Everyday Living: On Family Practices and Family Imaginaries.” The Sociological Review 65 (4): 865-81.

Ravelingien, An, Veerle Provoost, and Guido Pennings. 2016. "Creating a Family through Connection Websites and Events: Ethical and Social Issues." Reproductive Biomedicine Online 33 (4): 522-28.

Ryan-Flood, Róisín. 2009. Lesbian Motherhood. Gender, Families and Sexual Citizenship. Basingstoke: Palgrave Macmillan.

Segal-Engelchin, Dorit, Pauline I. Erera, and Julie Cwikel. 2012. "Having It All? Unmarried Women Choosing Hetero-Gay Families.” Affilia 27 (4): 391-405.

Sevón, Eija. 2012. “My Life Has Changed, but His Life Hasn't': Making Sense of the Gendering of Parenthood during the Transition to Motherhood." Feminism \& Psychology 22 (1): 60-80. https://doi.org/10.1177/0959353511415076.

Silverman, David. 2001. Interpreting Qualitative Data. London: Sage.

Smart, Carol. 2007. Personal Life. New Directions in Sociological Thinking. Cambridge, UK: Polity Press.

Sullivan, Maureen. 2004. The Family of Woman: Lesbian Mothers, Their Children, and the Undoing of Gender. Berkeley: University of California Press.

Taylor, Bridget, and Hilde de Vocht. 2011. "Interviewing Separately or as Couples? Considerations of Authenticity of Method." Qualitative Health Research 21 (11): 1576-87.

Thomson, Rachel, Mary Jane Kehily, Lucy Hadfield, and Sue Sharpe. 2011. Making Modern Mothers. Bristol, UK ; Portland, OR: Policy Press. 
Weeks, Jeffrey. 1989. Sex, Politics \& Society. The Regulation of Sexuality since 1800. 2e ed. London \& New York: Longman.

Witt, Emily. 2016. Future Sex. New York: Farrar, Straus and Giroux.

\section{Notes}

${ }^{1}$ Most reproductive medical service are publicly funded in Belgium and up to six stimulated cycles are reimbursed until the age of 43 .

${ }^{2}$ There were two co-parenting cases in which the mother's lesbian partner did not want a child. In one case, the couple ended up splitting up when the child was one. In the other, the mother's partner eventually accepted the parental project and got fully involved in it.

${ }^{3}$ Since Belgian school ends at noon on Wednesdays.

4 Two co-parenting cases were composed of respectively five and six adults around two children.

${ }^{5}$ In view of the fathers' conciliatory attitude and approval, one can wonder whether gay men with higher demands in terms of parenting involvement would have either given up the coparenting idea or would have turned to other parental routes. 